\title{
ADAPTATION OF A PHOTOVOLTAIC POWERED OZONE GENERATION SYSTEM FOR FOOD STORAGE
}

\author{
L.Nehari $^{1}$, M.Brahami ${ }^{1}$, IS.Bousmaha ${ }^{1}$, H.Labair ${ }^{2}$, FZ Boudjella ${ }^{1}$, A. Tilmatine ${ }^{2 *}$ \\ ${ }^{1}$ ICEPS Laboratory, Djillali Liabes University of Sidi Bel-Abbes, Algeria \\ ${ }^{2}$ APELEC Laboratory, Djillali Liabes University of Sidi Bel-Abbes, Algeria \\ *atilmatine@gmail.com
}

https://doi.org/10.34302/2019.11.4.5

\section{Article history: \\ Received:}

29 July 2019

Accepted:

29 September 2019

Keywords:

Power supply;

Ozone generator;

Food storage;

Photovoltaic energy.

\begin{abstract}
This paper is aimed to describe a low-cost system, including a power supply, an ozone generator and a photovoltaic panel for the disinfection of a food storage space. The "supply- ozone generator" system is powered by a photovoltaic energy system developed in the laboratory. The experiments were conducted using an ozone treated food storage cabinet and another control cabinet. The obtained results showed that an ozone concentration in the range 2 to $7 \mathrm{ppm}$ make it possible to ensure effective disinfection. The study that was carried out with fresh food products confirmed the effectiveness of such a technique for extending the shelf life of food, which can be used in isolated rural areas that are not provided with electrical energy.
\end{abstract}

\section{Introduction}

Ozone $\left(\mathrm{O}_{3}\right)$ is a potent and effective germicide oxidant. It has a much higher disinfection potential than chlorine and other disinfectants. Thus, it is widely used in the disinfection of air and water, chemicals and some pharmaceutical applications (JS Chang ET al.1995; A Fridman et al.2005; N Bouregbaa et al. 2014; Roya et al. 2016).

Dielectric barrier discharge (DBD) is considered as the most suitable kind of gas discharges for large-scale industrial applications. This silent discharge is nowadays widely used for ozone generation and several other industry applications such as surface treatment and biomedical application (Brahami, M. $\mathrm{N}$ et al. 2015; S Pekárek. 2012; S Boonduang. 2012).

The ozone is produced in industry mainly by electrical discharge and ultraviolet radiation (UV). UV ozone generators are in general not very expensive but ineffective (Drews et al.
2011). They require an exposure of the gas inside an UV reactor of great length while producing ozone with only weak concentration. Thus, the dielectric barrier discharge (DBD) is currently preferred for the production of high concentration ozone and higher gas outputs (Sainct et al. 2011; Fang et al. 2008).

The DBDs are well known for more than a century. Siemens carried out the first experiments on such discharges in 1857 (Kogelschatz et al. 2003). Although this method is very useful, the main disadvantage of DBDs is lack of uniformity. This is because at atmospheric pressure DBD is normally a filamentary discharge (D Trunec et al.2010). Since ozone cannot be stored, it must be generated on site. The reason for the different configurations of dielectric is due to the multiple applications of the DBD (Figure 1). 


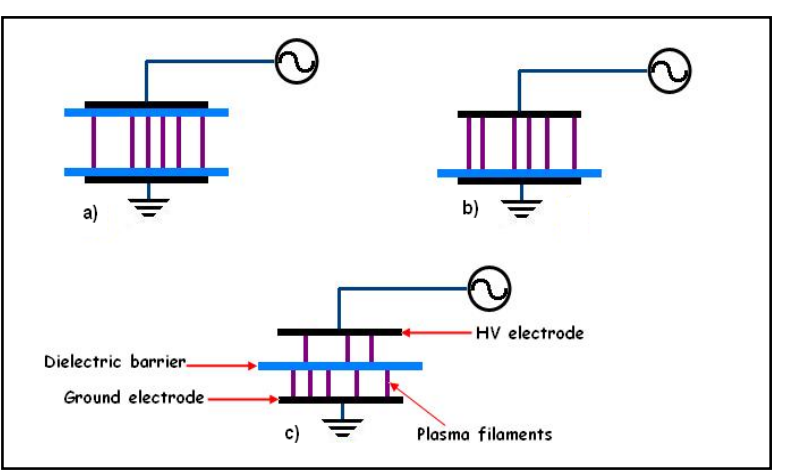

Figure 1. Dielectric barrier discharge with a gas gap

a) The dielectric is located on each electrode

b) The dielectric is located on one of the electrodes

c) The dielectric is located between the two electrodes in the gas

For example, in the case of waste gases sterilization and ozone generation, at least one electrode is covered by a dielectric. While for DBD new-generation lamps, the gas in the lamps is completely isolated from the metallic electrodes, which are covered with a dielectric layer. In this way, gas contamination is prevented and the lifetime of the lamps is enhanced (Williamson et al.2006)

The application field of ozone generation by DBD discharge is wide; the one focused in this work is about air disinfection in food storage rooms.

Generally, households are confronted with the problem of storage of fruits and vegetables. Food storage is carried out in cold rooms at low temperature (below $10{ }^{\circ} \mathrm{C}$ ) whose electrical operating power is relatively high $(2000 \mathrm{~W}$ for a volume of $20 \mathrm{~m}^{3}$ ), requiring thus a great amount of electrical energy. Therefore, because of the high cost for implementing the necessary equipment for cold rooms, the high electricity consumption and the precarious financial situation of third world countries, it is difficult to build cold rooms with its requested electrical energy in isolated sites. (M Jbilou et al .2018, Tayyari et al, 2017)

The objective of this paper is to develop a low cost system including an electronic power supply feeding an ozone generator, the whole being powered by a photovoltaic energy panel.
The system "supply-Ozone Generator-PV Panel" was used for disinfection of the air inside a food storage cabinet.

\section{Materials and methods \\ 2.1. Experimental setup}

The developed experimental device consists of a photovoltaic generator (1), a power supply (2) and an ozone generator (3) (Figure 2). The experimental setup used in this work is illustrated in Figure 3.

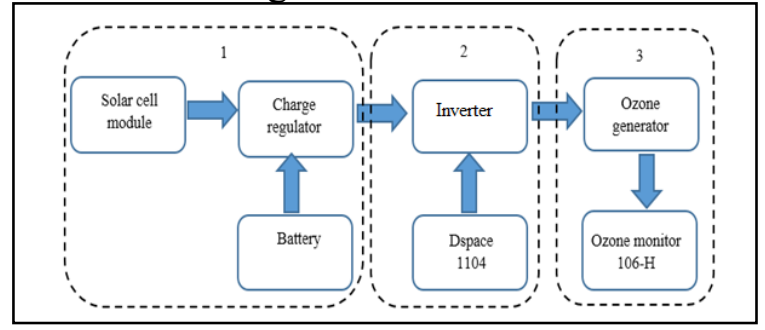

Figure 2. Descriptive diagram of the developed system

1- Photovoltaic Generator, 2- power supply,

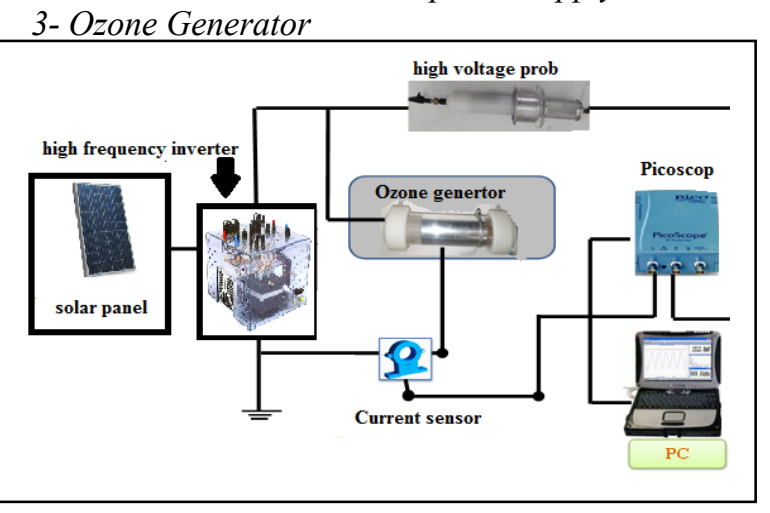

Figure 3. Descriptive schematic of the experimental setup

The photovoltaic generator consists of a 135-watt solar panel, a storage battery and a charge controller. This generator provides a voltage of $24 \mathrm{VDC}$ at the inlet of the DC-AC inverter, which transforms it to $2.3 \mathrm{kV} \mathrm{AC}$ voltage at a frequency of $14 \mathrm{kHz}$ using a ferrite transformer.

For the ozone generator, we opted for a dielectric barrier discharge gap of $1 \mathrm{~mm}$, which is the value generally used in industry and laboratory research (Figure 4). The inner cylindrical high voltage electrode is an adhesive aluminum sheath with $130 \mathrm{~mm}$ length inserted 
in a glass tube with a closed contact of their surfaces. The glass tube of thickness $1.5 \mathrm{~mm}$, acting as a dielectric barrier, is $200 \mathrm{~mm}$ long and $23 \mathrm{~mm}$ inner diameter. The grounded cylindrical electrode is a stainless steel tube of $200 \mathrm{~mm}$ length and $28 \mathrm{~mm}$ inner diameter.

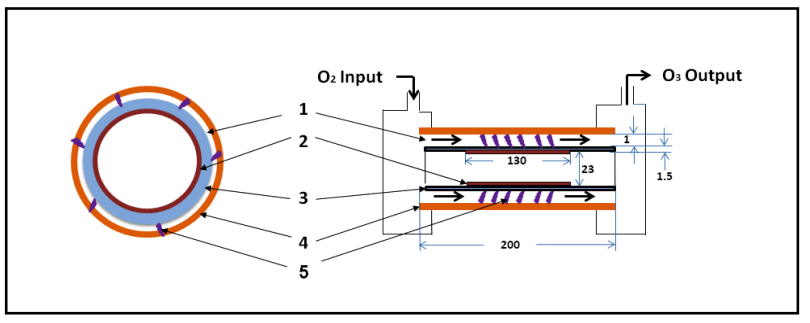

(a)

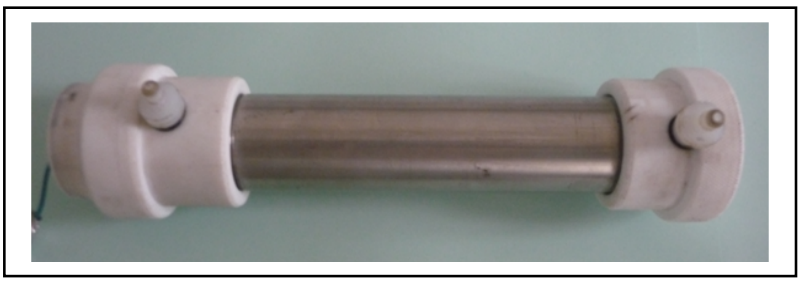

(b)

Figure 4. The ozone generator. (a) Descriptive schematic, (b) Photography of the ozone generator

1-Discharge gap (gas flow), 2-High voltage electrode, 3Glass tube, 4-Grounded electrode, 5-Plasma. (All dimensions are in $\mathrm{mm}$ )

\subsection{Description of the power supply}

Ozone generators are usually supplied by a high-voltage, high-frequency power supply, since high frequencies decrease the necessary power to be used and increase the ozone production rate (Flores-Fuentes et al.2009; Alonso, 2002; Alonso, 2003). Thus, the power density applied to the discharge surface is increased as well as the ozone generation rate, for a given surface area, while the necessary voltage is decreased. The increase in the frequencies up to several kilohertz is now feasible using power electronic switching devices, such as MOSFETs (Ponce-Silva, 2016; Amjad, 2012; Amjad, 2013). The main components of the developed inverter are shown in Figure 5.
- Control block: A DSPACE 1104 board generates the control signals sent to the power switches isolated using opto-couplers.

- Power Interface Block: This part represents an isolation and amplification interface that protects the control circuit $(5 \mathrm{~V})$ from the power circuit (220V/1A).

- Power unit (inverter): A Semikron block (inverter) based on the IGBTs package equipped with a free-wheeling diode has been used, it converts the $\mathrm{DC}$ voltage into $\mathrm{AC}$ voltage by means of the DSPACE 1104 board.

As IGBT reliability decreases with increasing temperature, the heating produced in these conductive junctions should be dissipated by heat sinks.

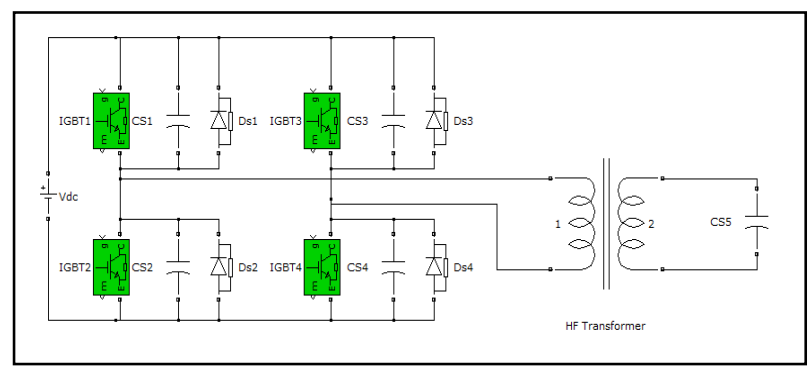

Figure 5. the developed inverter

\section{Results and discussion}

The switches are controlled by a square wave signal of amplitude $5 \mathrm{~V}$ delivered by DSpace card at a frequency of $14 \mathrm{kHz}$, as shown in Figure 6 While Figure 7 illustrates the voltage waveform supplying the ozone generator, which has a sinusoidal shape and can reach values greater than $2 \mathrm{kV}$.

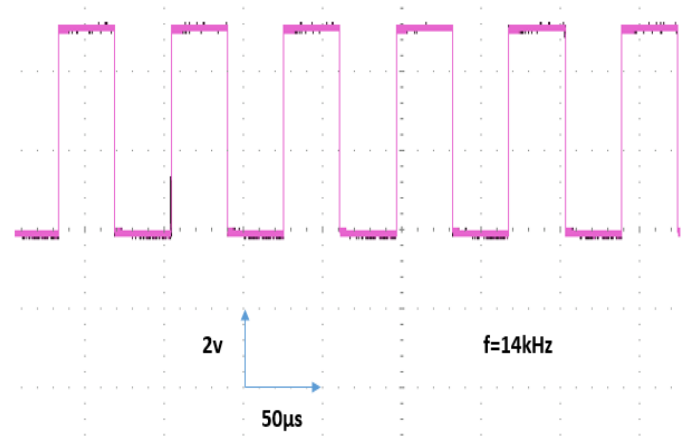

Figure 6. Command signal delivered by DSpace card 


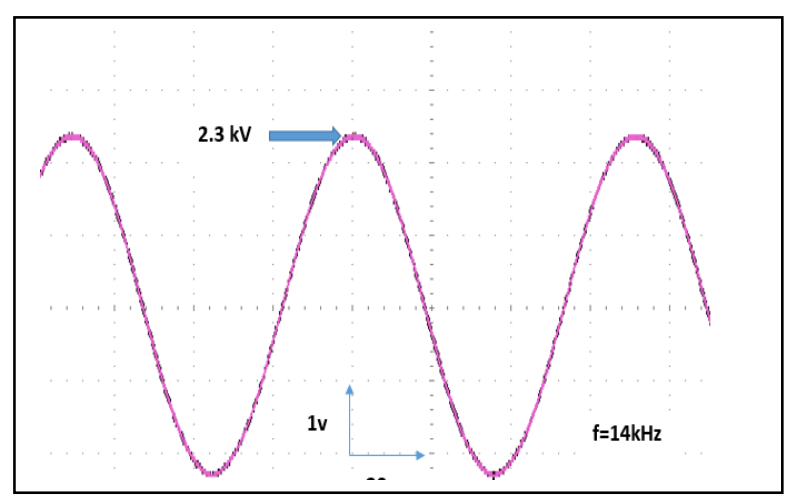

Figure 7. High voltage waveform supplying the ozone generator

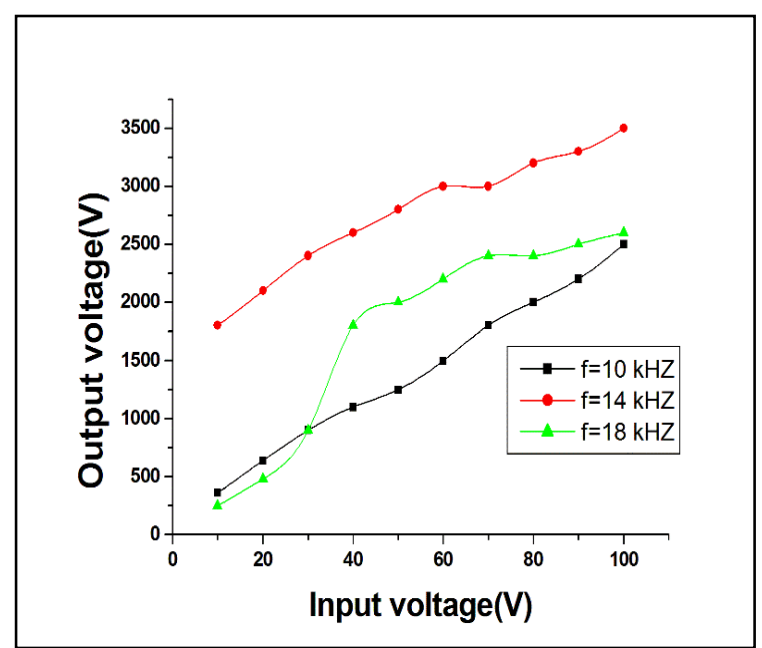

Figure 8. Variation of the output voltage supplying the ozone generator as a function of the inverter input voltage, for different values of the frequency

As shown by the obtained results plotted in Figure 8, representing the variation of the output voltage according to the input voltage, we note that the output voltage increases almost linearly with the input voltage, regardless of the frequency value. It is thus recommended to set the frequency at $\mathrm{f}=14 \mathrm{kHz}$, which represents the resonance frequency giving the maximum voltage value of the ozone generator.

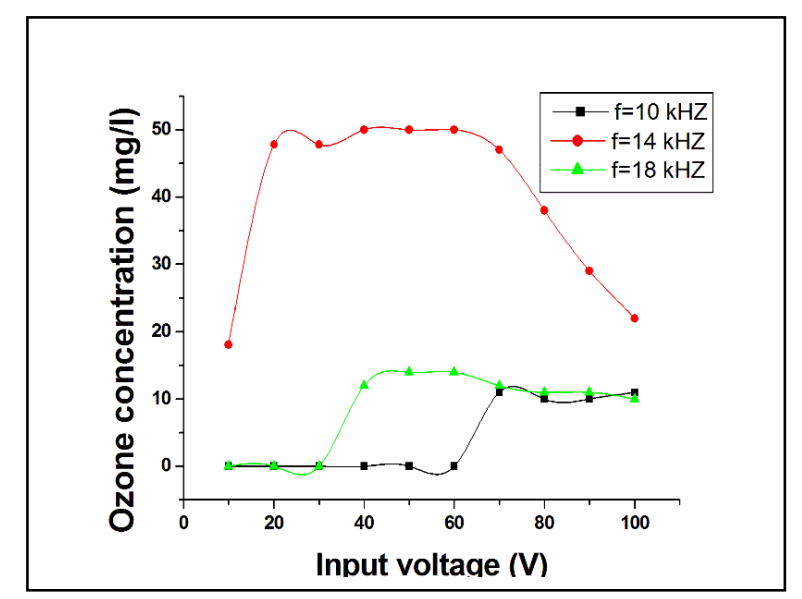

Figure 9. Variation of the ozone concentration as a function of the inverter input voltage Ue for different values of the frequency

These results have been definitively confirmed by the ones plotted in Figure 9 representing the variation of the ozone concentration as a function of the input voltage, for several values of the frequency. Indeed, it's shown that the ozone generator delivers the highest ozone concentration $\mathrm{CO}^{3}=50 \mathrm{mg} / \mathrm{l}$ at a frequency $\mathrm{f}=14 \mathrm{kHz}$ and for an input voltage $\mathrm{Ue}=24 \mathrm{~V}$. Therefore, we opted for these values in the following experimental study presented in this paper.

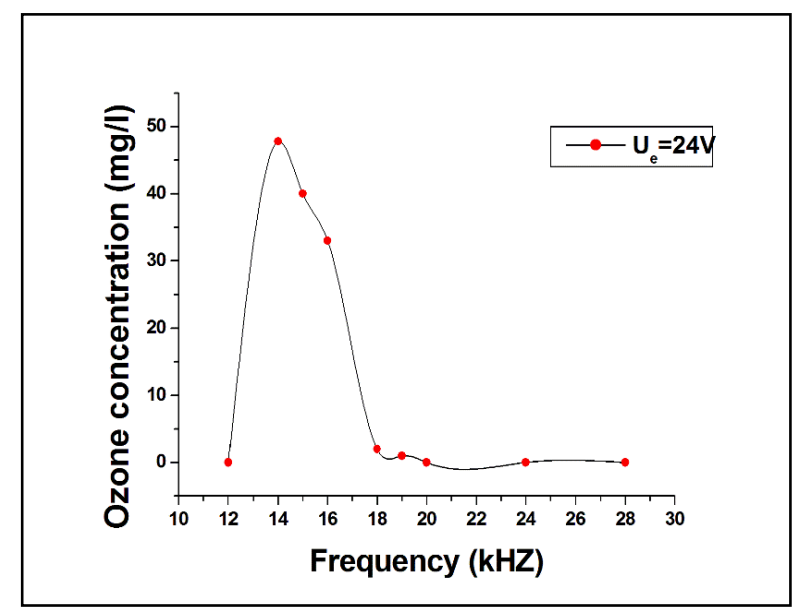

Figure 10. Variation of the ozone concentration as a function of the frequency $(\mathrm{Ue}=24 \mathrm{~V})$

Moreover, we plotted the variation of the ozone concentration as a function of the frequency for a constant voltage $\mathrm{Ue}=24 \mathrm{~V}$ showed in Figure 10. We see that $\mathrm{f}=14 \mathrm{kHz}$ is 
indeed the optimal resonance frequency giving maximum ozone concentration.

In addition, the developed system comprising the inverter and the ozone generator, was powered by a PV panel for its application for disinfection of food storage spaces to extend their shelflife. This system was tested and studied during a cloudy day, which was subdivided into 3 time slots according to the direction of the sun's rays.

In Figure 11 is represented the variation of the power generated by the PV in the three time intervals during a cloudy day with an average temperature of $18^{\circ} \mathrm{C}$. For each time interval, the inclination angle $\beta$ was modified so that the panel surface becomes perpendicular to the sun's rays.

According the results plotted in Figure 11, we see that the average power generated by the $\mathrm{PV}$ system remains higher than $60 \mathrm{~W}$, which is a sufficient value to supply the ozone generator that will be used for the air disinfection in food storage room. Power fluctuations are due to intermittent cloud shifts that cover more or less larger portion of the PV panel surface, thereby affecting its performance.

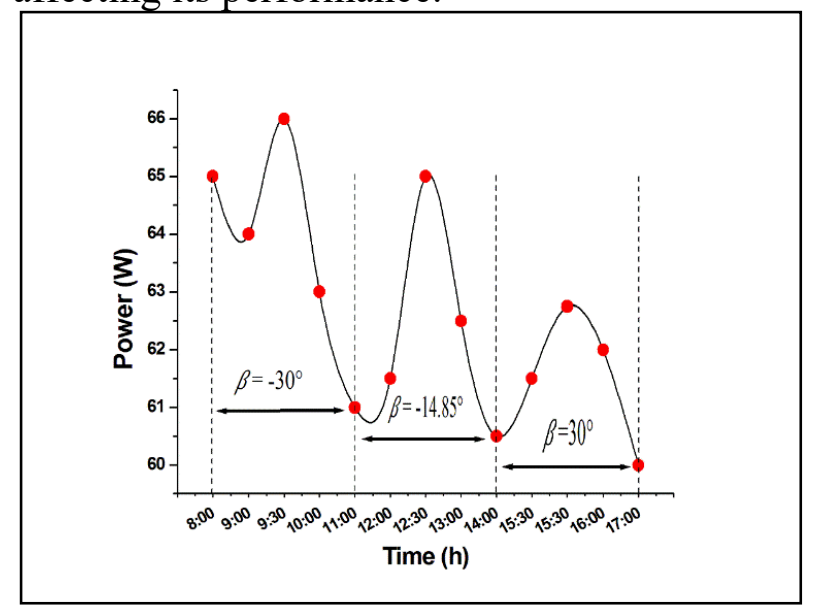

Figure 11. Daily variation of the power generated by the PV system in cloudy weather

with adjustment of the inclination angle $\beta$

The "inverter- ozone generator" system is used for the treatment of air in a food preservation enclosure. The experimental device used described in Figure 12 is a glass enclosure inside which the food products are placed. A supply system, comprising the ozone generator and the PV energy device shown in Fig. 3, is used to inject ozone into the enclosure through a PVC pipe fixed on the upper wall to diffuse ozone throughout the enclosure.

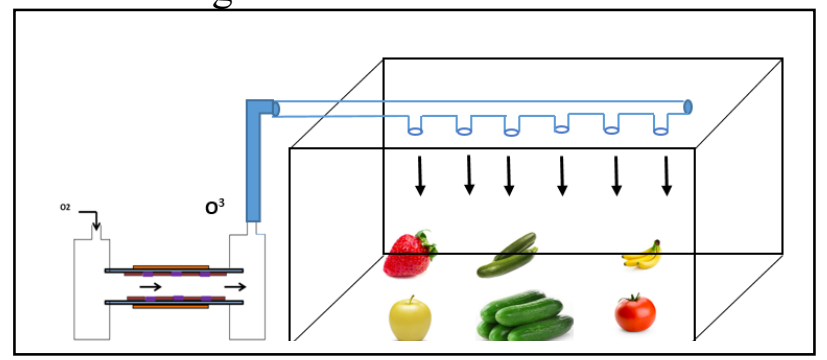

Figure 12. Schematic descriptive of the experimental setup

Ozone is mainly used for the disinfection of air and water, in order to eliminate bacteria and viruses. Nevertheless, the concentration should not exceed a maximum limit that will produce the opposite effect. The recommended amount of ozone in food industry should be comprised between 2 and $7 \mathrm{ppm}$ for effective food preservation, the average ozone concentration in our case has been kept in this range. Note that a second similar untreated chamber was used as a control enclosure.

Fresh food purchased at the local market was placed in both enclosures and kept for a period of 25 days. Photos were taken at regular intervals for visual analysis of food quality. All experiments were performed under stable climatic conditions of temperature $\left(20 \pm 8^{\circ} \mathrm{C}\right)$ and humidity $(50 \pm 15 \%)$.

\subsection{Application for food preservation}

The first step is to determine the operating times of the system to ensure a suitable ozone concentration lying between 2 and $7 \mathrm{ppm}$. The generator is run for a determined time period $\Delta t_{\text {ON }}$ up to a concentration of $7 \mathrm{ppm}$ and then it is turned off for a period $\Delta$ toff $_{\text {ontill a }}$ concentration of $2 \mathrm{ppm}$. As soon as the concentration reaches $2 \mathrm{ppm}$, the generator is restarted again. This regulation is performed automatically using an Arduino based system. 


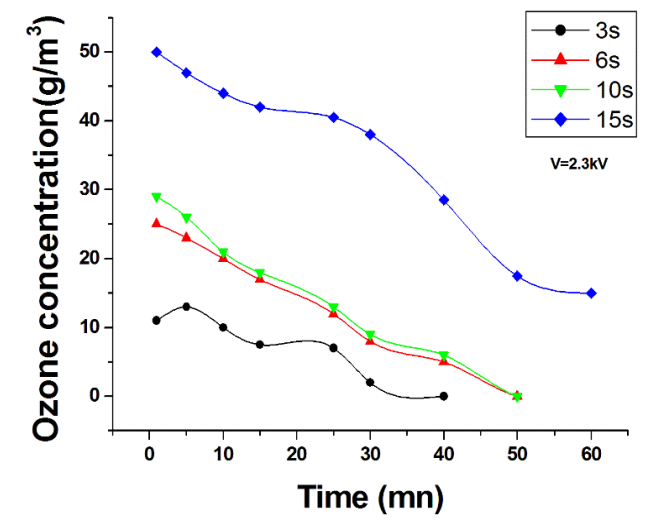

Figure 13. Evolution of the ozone concentration decline as a function of time during the turn off period $\Delta t_{\text {Off, }}$ for different values of the operating time period $\Delta t_{\mathrm{ON}}$

Figure 13 represents the evolution of the ozone concentration decline as a function of time when the generator is turned off during the period $\Delta t_{\text {off, }}$ each curve corresponding to an operating time $\Delta t_{\mathrm{ON}}$ of the ozone generator.

As shown in Figure 13, the time period required to reach an ozone concentration of 7 ppm is 15 seconds. Moreover, the time during which the concentration decreases from 7 to 2 ppm, depending on the experimental conditions of temperature and humidity, is approximately equal to 40 minutes.

Based on these results, the time control system of the ozone generator has been set to maintain an ozone concentration between 2 and $7 \mathrm{ppm}$. Consequently, an operating time of $\Delta \mathrm{t}_{\mathrm{ON}}$ of 15 seconds at turn off intervals of 40 minutes was adopted.

Food preservation results were compared with another control untreated air enclosure, in which similar foods were placed. The results were expressed in terms of number of storage days by taking daily pictures. The obtained results are shown by the images in Figure 14.

These results clearly show that food products stored in the ozone-treated enclosure are much more resistant to contamination than the products placed in the untreated enclosure. Ozone eliminates bacteria and slows their growth.
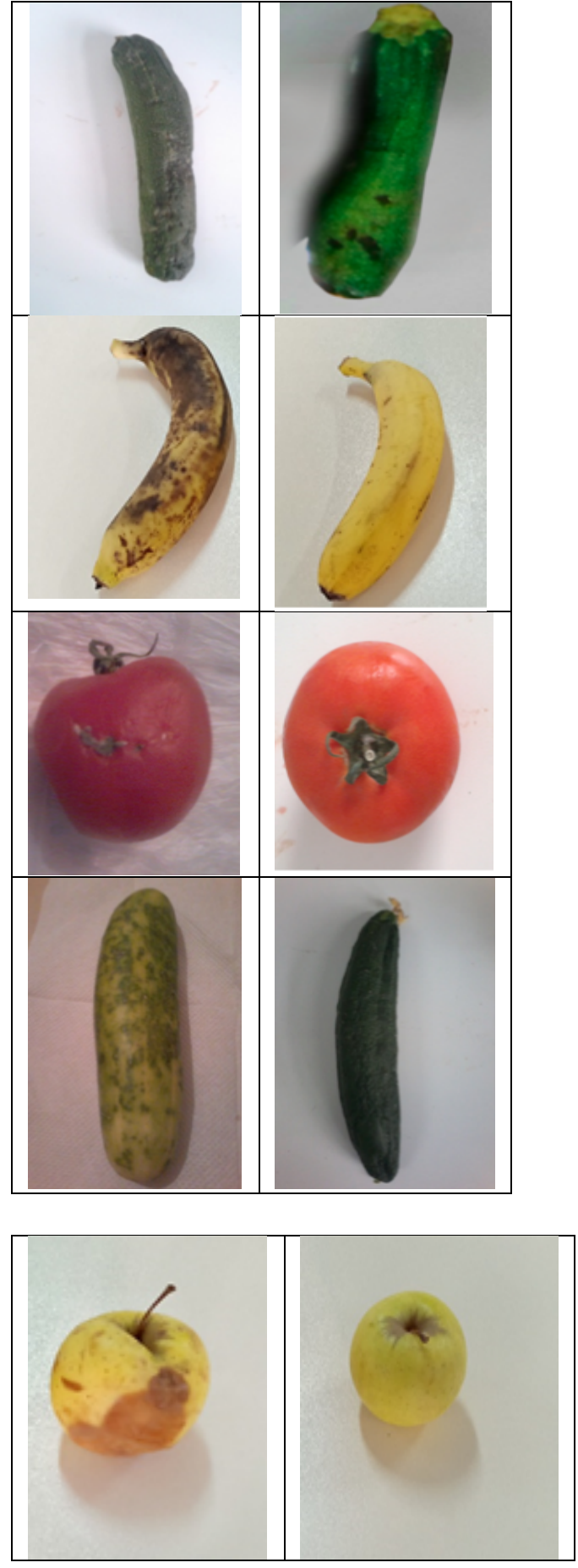

Figure 14. Photographs taken after 25 days period of storage

Left: untreated; Right: ozone treated

The production of ozone by DBD reactor is an effective mean for air disinfection and represents a well-adapted solution in the agrifood sector. 


\section{Conclusions}

Ozone is an effective solution for air disinfection. A system comprising a PV panel supplying a power supply and an ozone generator has been developed and used for the disinfection of food products stored in an ozonetreated enclosure. Moreover, an estimate of the energy produced by the PV panel has been estimated under cloudy conditions. The results obtained have shown that such a system using a high frequency power supply can be envisaged in the storage spaces located in isolated regions. Indeed, encouraging lengthening of the storage duration results have been obtained.

\section{References}

A. Fridman, A. Chirokov, A. Gutsol.(2005) «Non-thermal atmospheric pressure discharges» Journal of Physics D: Applied Physics,38,pp.1-24.

Alonso, J. M., Rico-Secades, M., Corominas, E., Cardesín, J., \& Garcia, J (2002, October) « Low-power high-voltage high-frequency power supply for ozone generation » In Conference Record of the 2002 IEEE Industry Applications Conference. 37th IAS Annual Meeting (Cat. No. 02CH37344) Vol. 1, 257-264.

Alonso, J. M., Valdés, M., Calleja, A. J., Ribas, J., \& Losada, J (2003) « High frequency testing and modeling of silent discharge ozone generators » OZONE SCIENCE \& ENGINEERING, 25(5), 363-376.

Alonso, M., Salam, Z., Facta, M., \& Ishaque, K (2012) «A simple and effective method to estimate the model parameters of dielectric barrier discharge ozone chamber» IEEE Transactions on Instrumentation and Measurement, 61(6), 1676-1683.

Amjad, M., Salam, Z., Facta, M., \& Mekhilef, S (2013) « Analysis and implementation of transformerless LCL resonant power supply for ozone generation» IEEE transactions on power electronics, 28(2), 650-660.

Boonduang, S., Limsuwan, S., Kongsri, W., \& Limsuwan, P (2012) «Effect of oxygen pressure and flow rate on electrical characteristic and ozone concentration of a cylinder-cylinder DBD ozone generator» Procedia Engineering, 32, 936942.

Bouregba, N., Benmimoun, Y., Meddah, B. Tilmatine, A., \& Ouldmoumna, A. (2016) «Ozonation of wastewater in Algeria by dielectric barrier discharge» Desalination and Water Treatment, 57(4), 1824-1835.

Brahami, M. N., Hadjeri, S., Nemmiche, S., Brahami, M., \& Tilmatine, A. (2015) «Experimental investigation of a PV solar generator for supplying water treatment process» International Journal of Environmental Studies, (1), 207-221.

Drews, J., Kusano, Y., Leipold, F., Bardenshtein, A., \& Krebs, N. (2011) «Ozone production in a dielectric barrier discharge with ultrasonic irradiation» Ozone: Science \& Engineering, 33(6), 483-488.

Fang, Z., Qiu, Y., Sun, Y., Wang, H., \& Edmund, K(2008) « Experimental study on discharge characteristics and ozone generation of dielectric barrier discharge in a cylinder-cylinder reactor and a wirecylinder reactor» Journal of Electrostatics, 66(7-8), 421-426.

Flores-Fuentes, A., Pena-Eguiluz, R., LópezCallejas, R., Mercado-Cabrera, A., Valencia-Alvarado, R., Barocio-Delgado, S., \& de La Piedad-Beneitez, A (2008) « Electrical model of an atmospheric pressure dielectric barrier discharge cell» IEEE Transactions on Plasma Science,37(1), 128-134.

J.S. Chang, A.J. Kelly, J.M. Crowley.(1995) «Handbook of Electrostatic Processes» Ozone Generation and Applications, vol, 26, 581- 605.

Jbilou, M, Brahami, M.N,Nemmich, S, Brahami, M., \& Tilmatine, A (2018) « OZONE FOOD STORAGE SUPPLIED BY PHOTOVOLTAIC ENERGY» Carpathian Journal of Food Science \& Technology,110(4).

Kogelschatz, U (2003) «Dielectric-barrier discharges: their history, discharge physics, and industrial applications» Plasma 
chemistry and plasma processing, 23(1), 146.

Pekárek, S. (2012) «Experimental study of surface dielectric barrier discharge in air and its ozone production» Journal of Physics D: Applied Physics, 45(7), 075201.

Roya, Amiri Qandashtani., Esmaeil, Ataye Salehi.( 2016). The effects clo2 \& o3 with map on microbial load reduction of mung bean sprouts. Carpathian Journal Of Food Science And Technology, 8 (4) , 121-127.

Sainct, F. P., Lacoste, D. A., Laux, C., MericamBourdet, N., Kirkpatrick, M., \& Odic, E (2011, July) « Efficiency of ozone generation by dbd and nrp discharges»» In 18th International Colloquium on Plasma Processes (CIP 2011),(p.3p).

Tayyari, Farinaz, Khazaei, Javad, AJAEI, Peyman, Jouki, Mohammad.(2017) « Effects Of Modified Atmosphere Packaging Systems, Low Temperature And Storage Time On The Quality Of Fresh Minimally Processed Pomegranate Arils» Carpathian Journal of Food Science \& Technology, 9(1) ,16-26.

Trunec, D, Zajíčková, L, Buršíková, V, Studnička,F,St'ahel,P,Prysiazhnyi,V,\& Franta, D (2010) «Deposition of hard thin films from HMDSO in atmospheric pressure dielectric barrier discharge» Journal of Physics D: Applied Physics, 43(22), 225403.

Williamson, J. M., Trump, D. D., Bletzinger, P., \& Ganguly, B. N (2006) «Comparison of high-voltage ac and pulsed operation of a surface dielectric barrier discharge» Journal of Physics D: Applied Physics, 39(20), 4400. 